\title{
RECOVERY FROM MASS EXTINCTION IN PELAGIC BIOTAS
}

\author{
NORRIS*, Richard D., Woods Hole Oceanographic Institution, Woods Hole, MA \\ 02543; BERGGREN, William A., Woods Hole Oceanographic Institution, Woods Hole, \\ MA 02543 U.S.A.
}

Mass extinctions profoundly affect patterns of diversification and skeletal innovation in the succeeding radiation. For instance, promising adaptations may be removed permitting traits of the few survivors to proliferate. Consequently, patterns of survivorship could control directions of radiation following the extinction event. Alternatively, selection during radiation may be quite different from extinction conditions. The founders may be quickly superseded by taxa with wholely new innovations that are built upon, but are distinct from, the founding morphologies.

Planktic foraminifera nearly became extinct at the end of the Cretaceous. Of the two or three lineages that survived, perhaps only one founded the bulk of the Paleocene radiation of Globigerinacea. In addition, there was little habitat diversification within the surviving lineages. Nearly all the morphological and ecological innovations occur in a single clade that diverged rapidly from the ancestral stock.

Neither of the best known surviving lineages diversified much after the Cretaceous. Hedbergella monmouthensis is the ancestor of Danian Globanomalina archaeocompressa. The two taxa are nearly identical in both morphology and in isotopic signature. Significantly, the globanomalinids displayed very little diversification, like their Cretaceous ancestors before them. Instead, species were replaced one after another in an anagenetic trend and consistently occupied a moderately deep-water habitat.

Similarly, triserial Guembelitria gave rise to only a modest radiation of biserial species in the earliest Danian primarilly within near surface water habitats.

Cladistic analysis suggests that the major part of the Cenozoic radiation was founded by one or two Cretaceous taxa. Most Danian trochospiral species abruptly radiated into two main stocks in the earliest Danian. All of them are probably derived from Hedbergella, but they rapidly became morphologically differentiated from this Cretaceous survivor. Alternatively, many of the features of the Danian species may have been inherited from another Cretaceous survivor--possibly a species of Rugoglobigerina--as suggested by comparative studies of early ontogeny. In either case, the group split rapidly into two main lineages. One, rooted in non-spinose 'Morozovella' taurica, led to the major diversification of the muricate-walled morozovellids. Isotopic data suggest this lineage spread from a moderately deep water habitat into the near-surface waters where the major diversification occurred. The other lineage developed spinose wall texture and gave rise to the diverse subbotinid radiation. Stable isotopic data suggests the subbotinids grew consistently in the coldest and presumably deepest waters. Their spinose wall texture suggests they were at least partly carnivorous, by analogy with living spinose taxa.

These patterns of morphological and ecological diversification suggest that the immediate survivors did not radiate markedly but retained the evolutionary rates and habitats of their Cretaceous ancestors. Most of the radiation occurred in a clade whose innovations evolved during the Danian, rather than simply retooling traits of their founder. Likewise, the radiation occurred principally in surface and deep water habitats, both largely vacated by the extinction event. The intermediate depth habitats were continuously occupied by the persistent hedbergellid-globanomalinid lineage. Their habitat was not invaded by other radiating clades. Evidently, survival alone does not confer the capacity for subsequent diversification upon a founding species. Innovation seems to be the key to dominance rather than mere persistence through an episode of heightened extinction. 